\title{
The integrated nutrition therapies for children with liver transplantation: an experience from Vietnam
}

\author{
Nguyen Thu Ha, Dao Thi Hao, Nguyen Dinh Phu
}

Department of Nutrition, 108 Military Central Hospital, Hanoi, Vietnam

Background: Undernourishment was associated with the high-risk factor of post-transplantation infection, mortality, mobility and length of hospital stay after pediatric liver transplant.

Methods: The study described the integrated nutrition therapies for the patient by phases of transplantation. The case study was a 14-year-old girl was with primary biliary cirrhosis and gastrointestinal bleeding, esophageal varices in 108 Military Central Hospital, Vietnam. Her nutritional status was assessed by small for gestational age (SGA), BMI-for-age (BAZ), and middle-upper-arm-circumference (MUAC).

Results: Before the transplant, the patient's SGA was C, BAZ -1.63 SD, and MUAC $18.5 \mathrm{~cm}$. She loss of appetite and anorexia. Dietitian used a combination of enteral and parenteral feeding for the patient to achieve the recommended intake. Her weight was stable until the surgery day. In the early post-transplant period, dietitians used both enteral and parenteral nutrition. The liquid diet with rice and water was applied on day 2 and day 3, 6-time per day, $50 \mathrm{~mL}$ each. From day 4 to day 7, she had nausea, vomit, and appetite disorder. The sum of energy was $900 \mathrm{kcal}$, with $1.7 \mathrm{~g} / \mathrm{kg}$ of protein. From day 8, she felt less anorexia and vomiting. The oral nutrition increased gradually with four meals with porridge, and two formulas enriched BCAA. The total energy was $1,582.7 \mathrm{kcal}$, and she received $1.6 \mathrm{~g} / \mathrm{kg}$ protein. SGA was B-level. From day 14, the intake of protein increased to $2.3 \mathrm{~g} / \mathrm{kg}$, with sources from beans, poultry, egg, fish, and vegetables. The six-meal diet was maintained (soups, rice, and formulas). From day 21 , the protein diet at $2.4 \mathrm{~g} / \mathrm{kg}$ was maintained. Sixty days after transplant, the liver function improved, the patient gained $37.5 \mathrm{~kg}$, SGA B, BAZ -1.56 SD, and MUAC $20.0 \mathrm{~cm}$.

Conclusions: Nutrition management planning based on three stages of liver transplantation was essential for pediatric patients. The suitable diet with the patient's eating habits showed positive effects on liver function and improved the children's nutritional status.

Corresponding author: Dao Thi Hao

E-mail: haohao8685@gmail.com

(c) The Korean Society for Transplantation

This is an Open Access article distributed under the terms of the Creative Commons Attribution Non-Commercial License (http://creativecommons.org/licenses/by-nc/4.0/) which permits unrestricted non-commercial use, distribution, and reproduction in any medium, provided the original work is properly cited. 